Biofouling. 2017 May 19; 33(6): 451-459. doi: 10.1080/08927014.2017.1322585.

\title{
Antibacterial effect of hydrogen peroxide - titanium dioxide suspensions in the decontamination of rough titanium surfaces
}

David Wiedmer $^{\mathrm{a}^{*}}$, Fernanda Cristina Petersen ${ }^{\mathrm{b}}$, Jessica Lönn-Stensrud $^{\mathrm{c}}$, Hanna Tiainen $^{\mathrm{a}}$

${ }^{a}$ Department of Biomaterials, Institute for Clinical Dentistry, University of Oslo, Oslo, Norway

${ }^{b}$ Department of Oral Biology, Faculty of Dentistry, University of Oslo, Oslo, Norway

${ }^{c}$ Science Library, University of Oslo, Oslo, Norway

*Corresponding author

Tel.: +47-22852350

Email: d.j.wiedmer@gmail.com

PO Box 1109 Blindern

0317 Oslo

Norway

\section{Contact details co-authors}

Fernanda Cristina Petersen:

PO Box 1052, Blindern, 0317 Oslo

f.c.petersen@odont.uio.no,+47-22840312

Jessica Lönn-Stensrud:

PO Box 1063, Blindern, 0317 Oslo

jessica.lonn-stensrud@ub.uio.no,+47-90850391

Hanna Tiainen:

PO Box 1109, Blindern, 0317, Oslo

hanna.tiainen@odont.uio.no,+47-22852354

\section{Funding}

This work was supported by Eureka-Eurostars Project under Grant E!8320 NuGel and the Norwegian Research Council Grant 257569. 


\section{Disclosure statement}

We hereby confirm that each of the authors has read and concurs with the content in the final manuscript. The material within has not been and will not be submitted for publication elsewhere except as an abstract. All authors have made substantial contributions to all of the following: (1) the conception and design of the study, or acquisition of data, or analysis and interpretation of data, (2) drafting the article or revising it critically for important intellectual content and (3) approving the final version of the submitted manuscript. 


\begin{abstract}
The chemical decontamination of infected dental implants is essential for the successful treatment of peri-implantitis. The aim of this study was to assess the antibacterial effect of a hydrogen peroxide - titanium dioxide $\left(\mathrm{H}_{2} \mathrm{O}_{2}-\mathrm{TiO}_{2}\right)$ suspension against Staphylococcus epidermidis biofilms. Titanium (Ti) coins were inoculated with a bioluminescent $S$. epidermidis strain for $8 \mathrm{~h}$ and subsequently exposed to $\mathrm{H}_{2} \mathrm{O}_{2}$ with and without $\mathrm{TiO}_{2}$ nanoparticles or chlorhexidine (CHX). Bacterial regrowth, bacterial load and viability after decontamination were analysed by continuous luminescence monitoring, live/dead staining and scanning electron microscopy. Bacterial regrowth was delayed on surfaces treated with $\mathrm{H}_{2} \mathrm{O}_{2}-\mathrm{TiO}_{2}$ compared to $\mathrm{H}_{2} \mathrm{O}_{2}$. $\mathrm{H}_{2} \mathrm{O}_{2}$-based treatments resulted in a lower bacterial load compared to $\mathrm{CHX}$. Few viable bacteria were found on surfaces treated with $\mathrm{H}_{2} \mathrm{O}_{2}$ and $\mathrm{H}_{2} \mathrm{O}_{2}-\mathrm{TiO}_{2}$ which contrasted with a uniform layer of dead bacteria for surfaces treated with $\mathrm{CHX} . \mathrm{H}_{2} \mathrm{O}_{2}-\mathrm{TiO}_{2}$ suspensions could therefore be considered an alternative approach in the decontamination of dental implants.
\end{abstract}

\title{
Keywords
}

Titanium dioxide, hydrogen peroxide, antibacterial agent, implant surface, biofilm, staphylococcus. 


\section{Introduction}

Peri-implantitis is defined as an inflammatory process around an osseointegrated dental implant (Zitzmann \& Berglundh 2008). It is characterized by the loss of surrounding bone and may ultimately result in total implant failure (Leonhardt et al. 2003; Quirynen et al. 2002). The formation and development of a bacterial biofilm on the implant surface has been suggested as the main causative factor of peri-implantitis (Quirynen et al. 2002; Renvert et al. 2012). Analogous to periodontitis, the infected lesion can trigger an inflammatory host response which causes the resorption of supporting alveolar bone by altering bone homeostasis (Darveau 2010; Heitz-Mayfield \& Lang 2010). The microbiota around infected implants is characterised by a high prevalence of Gram-negative anaerobes similar to the pathogenesis of periodontitis (Botero et al. 2005; Heitz-Mayfield \& Lang 2010; Mombelli \& Lang 1998). However, several other microorganisms, such as Staphylococcus aureus, Staphylococcus epidermidis and Candida albicans, can also be found at failing implants (Kronström et al. 2001; Leonhardt et al. 1999; Persson \& Renvert 2014).

Most treatment strategies aim at debridement of granulation tissue and decontamination of the implant surface to prevent reinfection and promote re-osseointegration (Claffey et al. 2008; Lindhe et al. 2008; Schwarz et al. 2011). However, success rates as low as $45 \%$ for the decontamination of dental implants have been reported for surgical treatment of peri-implantitis (Carcuac et al. 2016). Remaining bacteria and biofilm components following decontamination are considered an important factor in the re-occurrence of peri-implantitis (Kreisler et al. 2005).

The complete removal of adhering bacteria from implant surfaces, or prevention of adhesion following surgical treatment, is virtually unachievable in the heavily colonized microbial environment of the oral cavity. Antibacterial agents generally show a reduced effect on biofilms (Larsen \& Fiehn 1996; Roberts \& Mullany 2010; Zaura-Arite et al. 2001) and the implant shape and surface morphology further hamper successful decontamination (Carcuac et al. 2015; Carcuac et al. 2016). Mechanical debridement is one common approach to physically remove biofilm from a contaminated surface. Several techniques, such as the use of curettes, brushes and $\mathrm{CO}_{2}$ lasers, have been suggested (Romanos et al. 2009; Schwarz et al. 2006). However, mechanical debridement alone may not be sufficient to access and decontaminate infectious sites. Therefore, adjunctive antibacterial treatment is generally recommended (Claffey et al. 2008; de Waal et al. 2013; Karring et al. 2005; Lindhe et al. 2008; Renvert et al. 2012). One 
common approach is to chemically decontaminate the implant surface by the local use of antiseptics such as hydrogen peroxide $\left(\mathrm{H}_{2} \mathrm{O}_{2}\right)$, chlorhexidine digluconate $(\mathrm{CHX})$ or citric acid (Bürgers et al. 2012; Gustumhaugen et al. 2014; Henderson et al. 2013). The choice of the chemical agent used is often based on the experiences from therapeutical treatment of periodontitis and the most effective agent for implant decontamination has not yet been identified (Claffey et al. 2008; Romanos et al. 2015).

The adjunctive use of locally applied $\mathrm{H}_{2} \mathrm{O}_{2}$ for the chemical decontamination of infected dental implants has shown promising results, both in vitro (Gustumhaugen et al. 2014; Henderson et al. 2013; Ungvári et al. 2010) and in vivo (Gosau et al. 2010; Leonhardt et al. 2003). Aqueous $\mathrm{H}_{2} \mathrm{O}_{2}$ solutions (3 - 6 vol.\%) are commonly used as an antiseptic in dental practice. $\mathrm{H}_{2} \mathrm{O}_{2}$ solutions may have several advantages over other chemical agents, such as a broad spectrum of activity against various pathogens and the absence of toxic by-products (Linley et al. 2012). The use of antiseptics in open wounds is controversial due to the cytotoxic activity of the agents which may impair wound healing (Atiyeh et al. 2009; Drosou et al. 2003; Giannelli et al. 2008). In contrast, aqueous $\mathrm{H}_{2} \mathrm{O}_{2}$ is considered safe for the use in open wounds and also has been showing to slightly enhance the proliferation of human epithelial cells (Ungvári et al. 2010).

The bactericidal effect of $\mathrm{H}_{2} \mathrm{O}_{2}$ is associated with its capacity to oxidize various cellular components through its intrinsic oxidative power and subsequent formation of free radicals (Linley et al. 2012; McDonnell \& Russell 1999). It has been shown that the antibacterial effect of $\mathrm{H}_{2} \mathrm{O}_{2}$ is significantly reduced for pathogens with intrinsic defence mechanisms, in particular pathogens with high catalase activity and the ability to form a protective biofilm (Gaupp et al. 2012; Mah \& O'Toole 2001; McDonnell \& Russell 1999; Stewart et al. 2000). Recent studies indicate that the oxidative power of $\mathrm{H}_{2} \mathrm{O}_{2}$ can be enhanced by the addition of titanium dioxide $\left(\mathrm{TiO}_{2}\right)$ particles due to non-photocatalytic formation of oxygen centred radicals at the $\mathrm{H}_{2} \mathrm{O}_{2}$ $\mathrm{TiO}_{2}$ interface (Sanchez et al. 2013; Wiedmer et al. 2016). So far, only two in vitro studies have investigated the antibacterial effect of such $\mathrm{H}_{2} \mathrm{O}_{2}-\mathrm{TiO}_{2}$ suspensions with different outcome. Both studies assessed the antibacterial effect in a $S$. epidermidis biofilm model. Henderson et al. (2013) found an increased removal of biofilm mass for $\mathrm{H}_{2} \mathrm{O}_{2}-\mathrm{TiO}_{2}$ suspensions compared to $\mathrm{H}_{2} \mathrm{O}_{2}$ alone. The bactericidal effect was not investigated in this study. A similar study by Gustumhaugen et al. (2014) could not confirm the positive effect of $\mathrm{TiO}_{2}$ particles in $\mathrm{H}_{2} \mathrm{O}_{2}$ in a 
biofilm mass and a viability assay. Therefore, there is no conclusive evidence for the antibacterial effect of $\mathrm{TiO}_{2}$ particles in aqueous $\mathrm{H}_{2} \mathrm{O}_{2}$ suspensions.

The main aim of the present study was to assess the antibacterial activity of $\mathrm{H}_{2} \mathrm{O}_{2}-\mathrm{TiO}_{2}$ suspensions in comparison to conventional decontamination with either $\mathrm{H}_{2} \mathrm{O}_{2}$ or $\mathrm{CHX}$. The use of the constitutive bioluminescent strain Staphylococcus epidermidis Xen43 allowed the nondestructive, real-time monitoring of bacterial regrowth on titanium implant surfaces after decontamination. Scanning electron microscopy (SEM) and confocal fluorescence microscopy after live/dead staining have been used as complementary methods to evaluate the outcome of decontamination. 


\section{Materials and Methods}

\section{Titanium coins and decontamination agents}

Commercially pure $(\mathrm{cp})$, machine shaped Ti coins (diameter $=6.2 \mathrm{~mm}$, height $=2 \mathrm{~mm}$ ) were surface modified to mimic a rough dental implant surface. The coins were grit-blasted with $\mathrm{TiO}_{2}$ particles (particle size $=180-220 \mu \mathrm{m}$ ) and further acid etched with 0.2 vol. $\%$ hydrofluoric acid. The modified surface resembled the commercially available OsseoSpeed ${ }^{\mathrm{TM}}$ implant surface (Astra Tech AB, Mölndal, Sweden). For a detailed description of the modification procedure and a detailed characterization of the surface see (Gustumhaugen et al. 2014). A summary of all tested groups is given in Table 1. The nanoparticles (Degussa P25, Evonik Degussa $\mathrm{GmbH}$, Hanau Wolfgang Germany) used for $\mathrm{H}_{2} \mathrm{O}_{2}-\mathrm{TiO}_{2}$ suspensions have a primary particle size of $23 \mathrm{~nm}$ and consist of a mixed crystal phase of $80 \%$ anatase and $20 \%$ rutile according to the manufacturer specifications. It has also been shown that these particles occur as stable agglomerates in aqueous suspensions at physiological $\mathrm{pH}$ (Wiedmer et al. 2016). All chemicals were purchased from Sigma Aldrich (Sigma Aldrich, St. Louis, USA) if not stated differently.

Table 1: Control surfaces and chemical agents used to treat contaminated Ti surfaces (exposure time $1 \mathrm{~min}$ ).

\begin{tabular}{|c|c|c|c|}
\hline Category & Group & Description & Manufacturer \\
\hline \multirow[t]{3}{*}{ Antibacterial agents } & CHX & 0.2 vol. $\%$ chlorhexidine digluconate & VWR (Oslo, Norway) \\
\hline & $\mathrm{H}_{2} \mathrm{O}_{2}$ & 3 vol. $\%$ hydrogen peroxide & $\begin{array}{l}\text { Sigma Aldrich (St. Louis, } \\
\text { USA) }\end{array}$ \\
\hline & $\mathrm{H}_{2} \mathrm{O}_{2}-\mathrm{TiO}_{2}$ & $\begin{array}{l}3 \text { vol. } \% \text { hydrogen peroxide }+ \\
1 \mathrm{~g}^{-1} \text { titanium dioxide (Degussa P25) }\end{array}$ & $\begin{array}{l}\mathrm{H}_{2} \mathrm{O}_{2} \text { : see above } \\
\mathrm{TiO}_{2} \text { : Evonik Degussa GmbH } \\
\text { (Hanau Wolfgang, Germany) }\end{array}$ \\
\hline \multirow[t]{5}{*}{ Control groups } & $\mathrm{H}_{2} \mathrm{O}$ & sterile, ultrapure milliQ water & - \\
\hline & $\mathrm{H}_{2} \mathrm{O}-\mathrm{TiO}_{2}$ & $\begin{array}{l}\text { sterile, ultrapure milliQ water }+ \\
1 \mathrm{~g} 1^{-1} \text { titanium dioxide }\end{array}$ & $\mathrm{TiO}_{2}$ : see above \\
\hline & PBS & sterile phosphate buffered saline & VWR (Oslo, Norway) \\
\hline & no bacteria & no inoculation with bacteria & - \\
\hline & no treatment & no exposure to chemical agent & - \\
\hline
\end{tabular}

\section{Bacterial culture and biofilm formation}

In this study, the genetically modified strain $S$. epidermidis Xen 43 was used as a model for biofilm formation on Ti coins. The strain was derived from the clinical isolate S. epidermidis 1457 , where the luxABCDE genes have been incorporated into the bacterial genome to create a constitutive bioluminescent strain. The engineered strain has been shown to be phenotypically equal to its parental strain (Vuong et al. 2008) and was kept as frozen stock cultures to avoid 
phenotypic changes due to passages. Calibration curves were determined to correlate luminescence and colony forming units (CFU) as well as $\mathrm{OD}_{600}$ and $\mathrm{CFU}$ (supplementary information, Figure SI 1).

Tryptic soy broth (TSB) was used as growth medium and incubation was performed in an aerobic atmosphere at $37^{\circ} \mathrm{C}$. Bacterial stocks of S. epidermidis Xen 43 were stored at $-80^{\circ} \mathrm{C}$ in $15 \%$ glycerol. Stocks were used to prepare diluted cultures at an initial optical density at $600 \mathrm{~nm}\left(\mathrm{OD}_{600}\right)$ of $0.05\left(\sim 1 \times 10^{7}\right.$ cells $\left./ \mathrm{ml}\right)$ as determined spectrophotometrically (Biophotometer, Eppendorf, Hamburg, Germany) before the suspension was incubated for 24 h. The overnight cultures were then diluted in TSB 1:100 and cultured overnight for a second time. The second overnight cultures were diluted in TSB 1:100 for $\mathrm{OD}_{600}=0.02-0.03\left(\sim 1 \times 10^{7}\right.$ cells $/ \mathrm{ml}$ ) and used to inoculate Ti coins. Coins were placed in a 48-well micro-titre plate (Nunc, Roskilde, Denmark) and inoculated with $700 \mu \mathrm{l}$ of bacterial suspension. The plate was then incubated for $8 \mathrm{~h}$ to allow colonization and biofilm formation on the Ti coins. After the incubation, all coins were transferred to a new 48-well plate and each well was filled with 500 $\mu 1$ sterile PBS, followed by the exposure to the antibacterial agents. A scheme of the experimental setup is given in Figure 1.

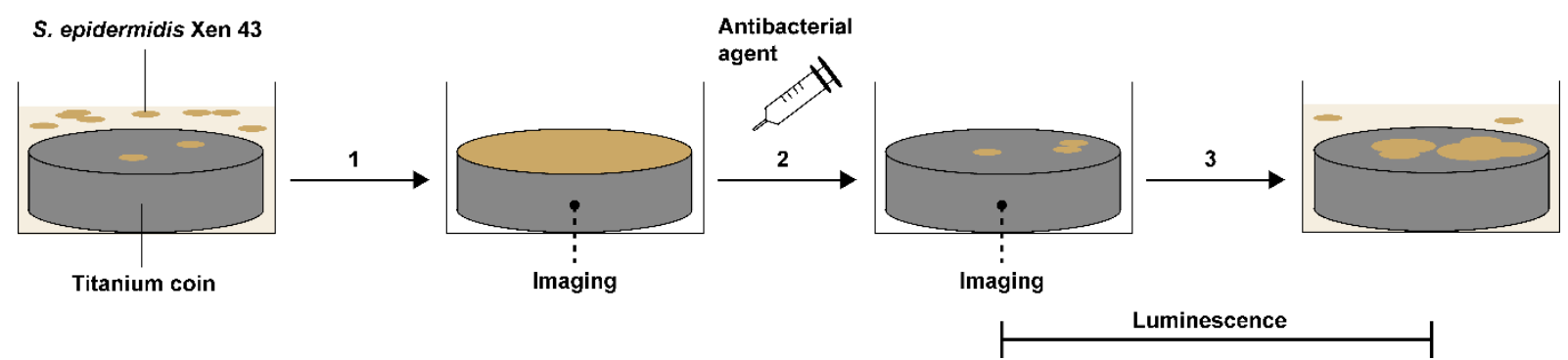

Figure 1: Scheme of the experimental setup. Ti coins were inoculated with S. epidermidis Xen 43 and (1) incubated for $8 \mathrm{~h}$ for biofilm formation. Contaminated samples were transferred to a new well and (2) exposed to chemical agents for 1 min. Decontaminated samples were rinsed with PBS and (3) reincubated in TSB for $24 \mathrm{~h}$. Luminescence was recorded every 15 min during reincubation. The decontamination outcome was further assessed by SEM and fluorescence microscopy after live/dead staining.

\section{Decontamination}

All samples, except the control surfaces, were transferred to wells filled with $500 \mu 1$ of chemical agents. $\mathrm{TiO}_{2}$ containing agents were vortexed for $10 \mathrm{~s}$ immediately before use. The treatment was stopped after $1 \mathrm{~min}$ by transferring the treated coins to separate wells filled with $1 \mathrm{ml}$ PBS. After transferring, all samples were carefully rinsed with sterile PBS three times to remove all chemical agents before further processing. All treatment groups were tested in three 
independent experiments, each consisting of eight samples (luminescence: $n=6$, scanning electron microscopy: $\mathrm{n}=1$, fluorescence microscopy: $\mathrm{n}=1$ ).

\section{Luminescence assay}

Regrowth of bacteria was measured by monitoring luminescence after decontamination. Six coins of each group were transferred to a new 96 optical well plate (Perkin Elmer, Waltham, USA) and wells were filled with $150 \mu$ l of pre-heated TSB. Afterwards, the well plate was sealed before incubation in a multi-detection microplate reader (Synergy HT, BioTek, Winooski, USA) at $37^{\circ} \mathrm{C}$. Luminescence expressed as relative light units (RLU) was recorded for $24 \mathrm{~h}$ in time intervals of $15 \mathrm{~min}$ with $10 \mathrm{~s}$ of moderate shaking immediately before measuring. Peaks in RLU are from now on referred to as $\mathrm{RLU}_{\max }$, time of reincubation until $\mathrm{RLU}_{\max }$ is reached is referred to as $\mathrm{tRLU} \mathrm{U}_{\max } . \mathrm{t}_{\mathrm{RLUmax} / 2}$ is defined as the time of reincubation until $50 \%$ of $\mathrm{RLU}_{\max }$ is reached and was used as a reference value to assess and compare the antibacterial effect of different agents. The luminescence assay was performed in randomised triplicates for a total sample number of $n=18$ per treatment group.

\section{SEM and fluorescence microscopy}

In addition to luminescence measurements, SEM and fluorescence microscopy after live/dead staining was performed directly after the treatment with different chemical agents. SEM imaging was performed in order to investigate the structure of the remaining biofilm after treatment with chemical agents. Samples for SEM imaging were fixated overnight in $2.5 \%$ glutaraldehyde in $0.1 \mathrm{M}$ Sørensen's phosphate buffer solution. Afterwards, samples were treated with ethanol $(70 \%, 80 \%, 90 \%, 95 \%$ and $100 \%$ ethanol) and further dehydrated by critical point drying before being sputtered with platinum $(\mathrm{Pt})$. SEM examination was done using a field emission scanning electron microscope (S-4800, Hitachi, Tokyo, Japan), and images were taken for three randomly selected areas on the surface.

A Live/Dead BacLight bacterial viability kit (Molecular Probes Inc., Eugene, USA) was used to determine the viability of remaining bacteria directly after the exposure to different chemical agents. $6 \mu 1$ propidium iodine and $6 \mu \mathrm{S}$ STO9 were diluted in $5 \mathrm{ml}$ sterile, ultrapure milliQ water. Samples were placed in a new 24-well plate and stained for $15 \mathrm{~min}$ in dark before they were rinsed with PBS in order to remove excess dye. Mounting oil was used to fixate a cover slip onto the Ti surfaces before imaging. A confocal fluorescent microscope (DM 6000 CFS, Leica, Wetzlar, Germany) was used to sequentially detect light emission for viable (green 
fluorescent) and dead (red fluorescent) bacteria. Images were derived from a full projection of a $20 \mu \mathrm{m}$ z-stack at a magnification of 40x taken at three randomly selected areas on the surface. Both SEM and fluorescence microscopy were performed in triplicates.

\section{Statistical analysis}

$t_{\text {RLUmax/2 }}$ for groups which showed bacterial regrowth is presented as mean values \pm standard deviation (SD). Datasets were analysed for normality (Shapiro-Wilk) and equal variance (Brown-Forsythe) before further testing. One way analysis of variance (ANOVA) was performed separately for antibacterial agents $\left(\mathrm{H}_{2} \mathrm{O}_{2}, \mathrm{H}_{2} \mathrm{O}_{2}-\mathrm{TiO}_{2}\right.$ and $\left.\mathrm{CHX}\right)$ and control agents $\left(\mathrm{H}_{2} \mathrm{O}, \mathrm{H}_{2} \mathrm{O}-\mathrm{TiO}_{2}\right.$ and $\left.\mathrm{PBS}\right)$. A subsequent pairwise comparison (Holm-Sidak) between data groups was run to determine statistically significant differences $(p<0.05)$ between agents of each category. Statistical significant differences are highlighted with an asterisk. 


\section{Results}

\section{SEM}

Untreated surfaces were almost completely covered with a dense biofilm of a thin biofilm of 13 bacterial layers, whereas the amount of bacteria was greatly reduced after the treatment with $\mathrm{H}_{2} \mathrm{O}_{2}$ or $\mathrm{H}_{2} \mathrm{O}_{2}-\mathrm{TiO}_{2}$ (Figure 2). Both groups showed only a few remaining clusters of bacteria distributed over the coin, particular in grooves and pits of the rough surface. Further, $\mathrm{TiO}_{2}$ agglomerates of varying size and morphology were found in all examined areas for $\mathrm{H}_{2} \mathrm{O}_{2}-\mathrm{TiO}_{2}$. SEM images of samples exposed to $\mathrm{CHX}$ showed a higher number of total bacteria than surfaces treated with $\mathrm{H}_{2} \mathrm{O}_{2}$-based agents. Bacteria were present in large colonies for $\mathrm{CHX}$ but the amount of bacteria was reduced compared to untreated samples. Representative SEM images of Ti surfaces before and after treatment with antibacterial agents are shown in Figure 2. SEM images for all control surfaces and control agents can be found in the supplementary information (Figure SI 2).
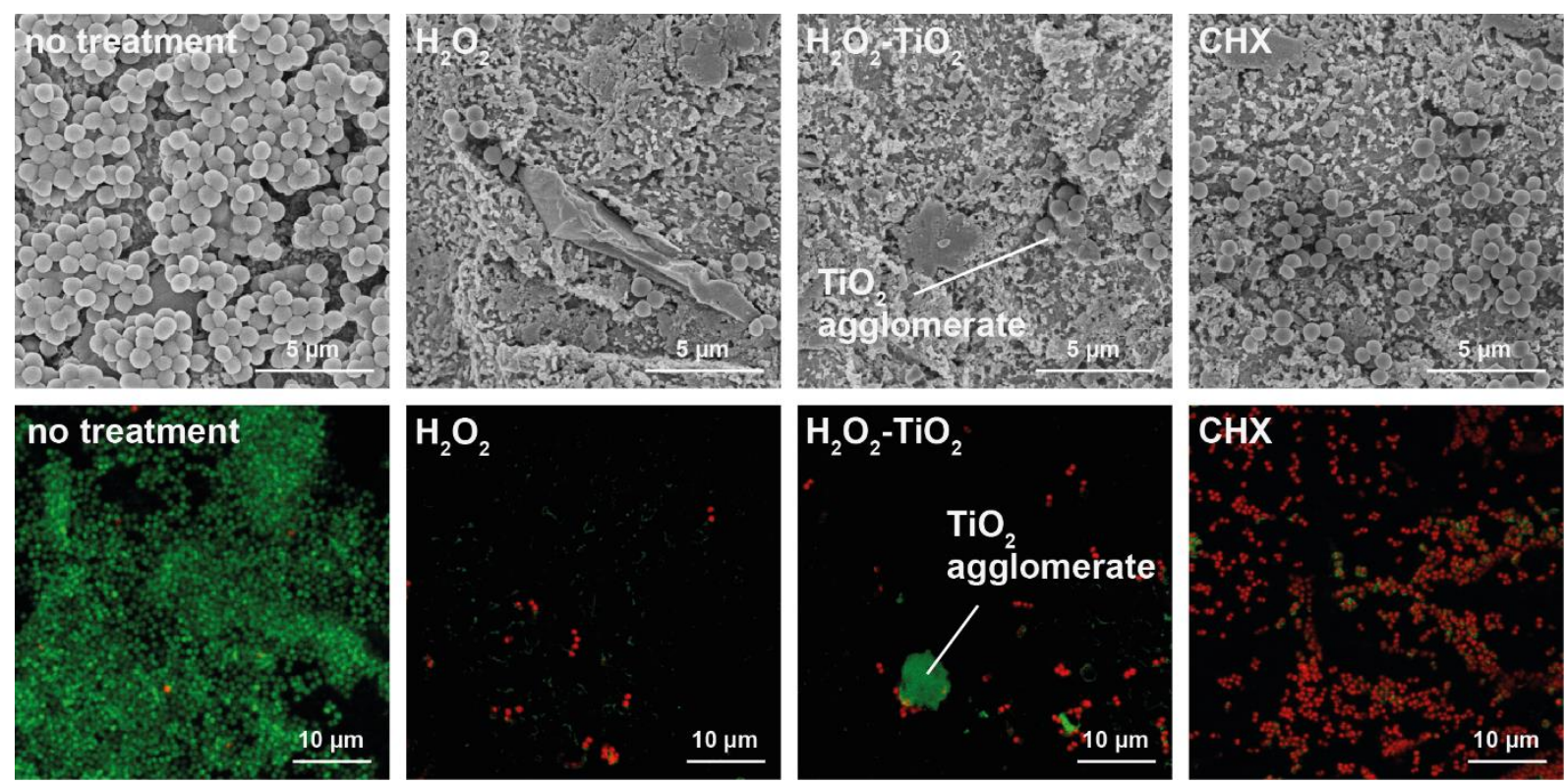

Figure 2: SEM (top row) and fluorescent micrographs (bottom row) of Ti surfaces before and after the treatment with different antibacterial agents. Bacteria stained green are considered viable while dead bacteria are stained red.

\section{Fluorescence microscopy}

Untreated biofilms consisted of mostly green fluorescent (viable) bacteria with only a few, isolated red fluorescent (dead) bacteria (Figure 2). Similar to SEM images, the treatment with $\mathrm{H}_{2} \mathrm{O}_{2}$ or $\mathrm{H}_{2} \mathrm{O}_{2}-\mathrm{TiO}_{2}$ resulted in a strong reduction of the total amount of biofilm. The remaining 
bacteria for these two groups were organised in clusters of mainly dead bacteria, although some viable bacteria were also present on these surfaces. $\mathrm{TiO}_{2}$ agglomerates which remained on the surface after treatment with $\mathrm{H}_{2} \mathrm{O}_{2}-\mathrm{TiO}_{2}$ were strongly green fluorescent. Live/dead staining further indicated that the high number of bacteria on surfaces treated with $\mathrm{CHX}$ were dead. Fluorescence microscopy images after live/dead staining before and after treatment are shown in Figure 2. Additional fluorescent images for all control surfaces and control agents can be found in the supplementary information (Figure SI 2).

\section{Luminescence assay}

A characteristic pattern for luminescence over time was found for all tested groups which showed bacteria regrowth: (1) an initial low RLU intensity was followed by (2) an exponential increase which resulted in a distinct peak (RLU $\left.U_{\max }\right)$ and (3) decreased until (4) a stationary level of RLU higher than (1) was reached (Figure 3). A linear correlation between CFU and RLU was valid for $\mathrm{t}=0 \mathrm{~h}-\mathrm{t}=\mathrm{t}_{\mathrm{RLUmax}}\left(\mathrm{R}^{2}=0.98\right.$, Figure SI 3). Both, $\mathrm{H}_{2} \mathrm{O}_{2}$ and $\mathrm{H}_{2} \mathrm{O}_{2}-\mathrm{TiO}_{2}$ showed bacterial regrowth within $24 \mathrm{~h}$ of reincubation following the characteristic curve progression described above. No regrowth was detected for CHX treated surfaces. The change in RLU intensity during reincubation after the treatment with the three antibacterial agents is plotted in Figure $3 \mathrm{~A}$ (means, $\mathrm{n}=18$ ). The corresponding data for groups treated with control agents and for control surfaces are provided in the supplementary information (Figure SI 3).
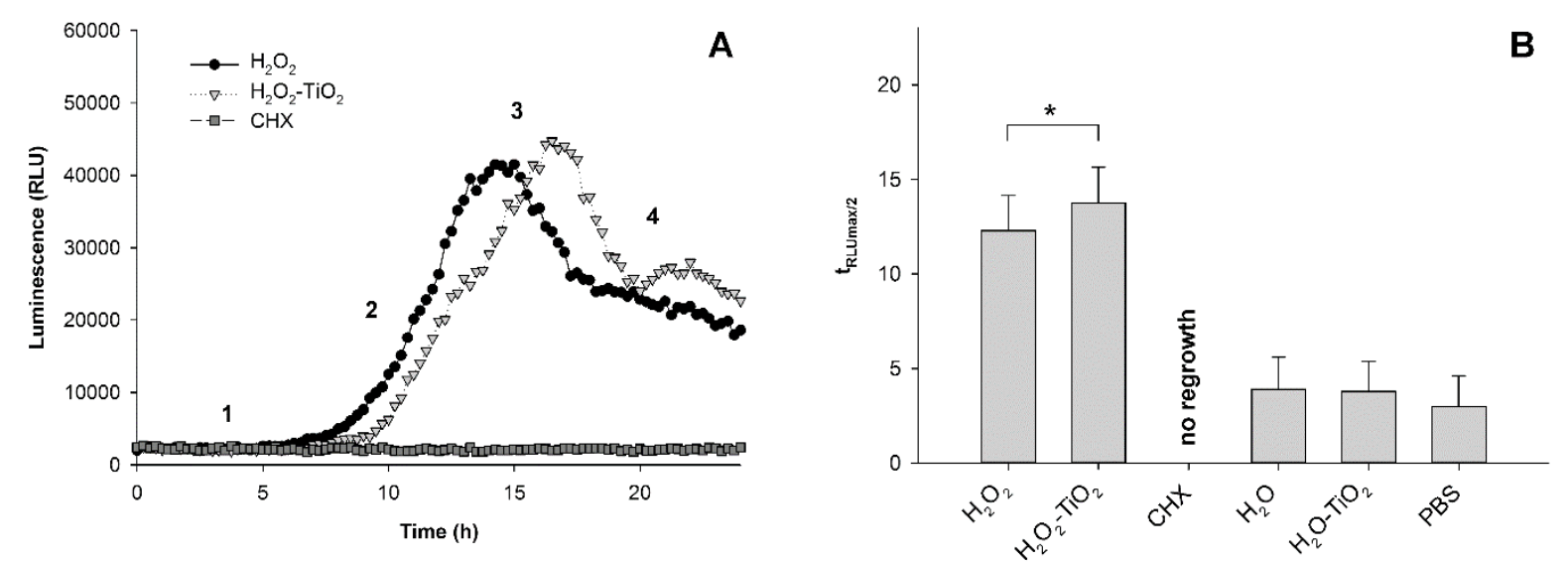

Figure 3: S. epidermidis regrowth after treatment with antibacterial agents (A). Luminescence measured during reincubation of Ti surfaces following the decontamination with the tested antibacterial agents $(\mathrm{mean}, \mathrm{n}=18)$. Characteristic segments of the curve progression are labeled 1 - 4 and are described in the discussion. (B) Time after treatment with antibacterial agents and control groups until $\mathrm{RLU}_{\max } / 2$ is reached (mean $\pm \mathrm{SD}, \mathrm{n}=18, *$ if $\mathrm{p}$ $<0.05$ for multiple comparison within one category). 
$t_{\text {RLUmax/2 }}$ is illustrated in Figure 3B for all treated surfaces. All antibacterial agents showed a strong delay in $t_{R L U m a x} / 2$ compared to the control agents. Importantly, the addition of $\mathrm{TiO}_{2}$ nanoparticles in aqueous $\mathrm{H}_{2} \mathrm{O}_{2}$ solutions resulted in an increased delay that was significant ( $\mathrm{p}$ $=0.028)$ compared to $\mathrm{H}_{2} \mathrm{O}_{2}$ alone $\left(\mathrm{H}_{2} \mathrm{O}_{2}-\mathrm{TiO}_{2}=13.75 \pm 1.90 \mathrm{~h}, \mathrm{H}_{2} \mathrm{O}_{2}=12.29 \pm 1.86 \mathrm{~h}\right)$. No statistically significant differences in $t_{R L U m a x} / 2$ were found between surfaces which had been treated with control agents $\left(\mathrm{H}_{2} \mathrm{O}=3.90 \pm 1.70 \mathrm{~h}, \mathrm{H}_{2} \mathrm{O}-\mathrm{TiO}_{2}=3.79 \pm 1.59 \mathrm{~h}\right.$ and $\mathrm{PBS}=2.99 \pm$ $1.63 \mathrm{~h})$. 


\section{Discussion}

The present study assessed the antibacterial effect of $\mathrm{TiO}_{2}$ nanoparticles in $\mathrm{H}_{2} \mathrm{O}_{2}$ solutions for chemical decontamination of dental implant surfaces. The effect was tested on S. epidermidis which readily forms mono-species biofilms on various substrates in vitro. The Ti substrate was completely covered with a thin, multilayer biofilm after incubation for $8 \mathrm{~h}$ and subsequently exposed to different antibacterial agents for $1 \mathrm{~min}$. Such a biofilm cannot entirely represent the complex structure of polymicrobial biofilms in peri-implantitis. However, S. epidermidis is one of the early colonizers in the formation of dental biofilm (Sbordone \& Bortolaia 2003) and has been found in biofilms of failing dental implants (Leonhardt et al. 1999). Further, it is a safe and well-established model to test the antibacterial activity of chemical agents on biofilms (Bürgers et al. 2012; Gustumhaugen et al. 2014; Henderson et al. 2013).

A bioluminescence assay was used to continuously monitor the metabolic activity and potential bacterial regrowth after the reincubation of decontaminated samples. Since bioluminescence is an energy demanding process, it can be used as a valuable indicator for the metabolic activity of microorganisms (D'Souza 2001; Marincs 2000). Linear correlation between RLU and CFU during the exponential growth phase (Figure SI 2) further makes luminescence a valid measure to describe the viability of bacteria which survive chemical decontamination and regrow on the implant surface. In addition, SEM and fluorescence microscopy were used to analyse $\mathrm{Ti}$ surfaces immediately before and after the exposure to different chemical agents and thereby complemented the findings of the luminescence assay.

The addition of $\mathrm{TiO}_{2}$ nanoparticles enhanced the antibacterial effect of $\mathrm{H}_{2} \mathrm{O}_{2}$ solutions and delayed the regrowth of bacteria on previously contaminated surfaces. The delay in $t_{R L U m a x / 2}$ for $\mathrm{H}_{2} \mathrm{O}_{2}$ suspensions which contained $\mathrm{TiO}_{2}$ nanoparticles was statistically significant compared to $\mathrm{H}_{2} \mathrm{O}_{2}$ solutions of the same concentration (Figure $3 \mathrm{~B}$ ). $\mathrm{TiO}_{2}$ nanoparticles did not show intrinsic antibacterial properties (Figure 3B), and hence, the delay in $t_{R L U m a x} / 2$ is suggested to be due to the interaction between $\mathrm{TiO}_{2}$ and $\mathrm{H}_{2} \mathrm{O}_{2}$. The non-photocatalytic formation of oxygen centred radicals, due to the interaction of $\mathrm{H}_{2} \mathrm{O}_{2}$ and $\mathrm{TiO}_{2}$, has previously been shown (Fenoglio et al. 2009; Sanchez et al. 2013; Wiedmer et al. 2016). These studies suggested that $\mathrm{TiO}_{2}$ can act as a Fenton catalyst and decompose $\mathrm{H}_{2} \mathrm{O}_{2}$ into oxygen centred radicals namely superoxide $\left(\mathrm{O}_{2}^{-{ }^{-*}}\right)$ and hydroxyl radicals $\left({ }^{\circ} \mathrm{OH}\right)$. The bactericidal effect of free radicals is undisputed and several cellular components have been identified as targets for radical mediated oxidation (Gaupp et al. 
2012; Halliwell \& Gutteridge 2007). However, the potential formation of radicals on the $\mathrm{TiO}_{2}$ catalyst could not abolish bacterial regrowth which was most likely due to remaining vital clusters after the decontamination (Figure 2).

One explanation for the relatively small increase in antibacterial activity may be the nature and location of the radicals formed at the $\mathrm{H}_{2} \mathrm{O}_{2}-\mathrm{TiO}_{2}$ interface. Earlier results indicated that primarily superoxide radicals $\left(\mathrm{O}_{2}^{-\bullet}\right)$ are formed at this interface and the oxidative effect is limited to the proximity of the surface (Wiedmer et al. 2016). Extracellular polymeric matrix (EPS) may protect bacteria from direct contact with $\mathrm{TiO}_{2}$ nanoparticles and thereby hamper the antibacterial effect. Further, there is evidence that $\mathrm{O}_{2}^{-\bullet}$ can adsorb to the metal oxide surface resulting in negative net surface charge of $\mathrm{TiO}_{2}$ in physiological $\mathrm{pH}$ (Anpo et al. 1999; Wiedmer et al. 2016). This may lead to unfavourable repulsive forces between the negatively charged $\mathrm{TiO}_{2}$ surface and the overall negatively charged bacterial wall which may further limit the bactericidal effect of formed free radicals.

The positive effect of $\mathrm{TiO}_{2}$ nanoparticles may also be masked by the presence of a more potent catalyst than $\mathrm{TiO}_{2}$ in the presented in vitro assay. Strong bubbling was observed on contaminated Ti surfaces approximately $15 \mathrm{~s}$ after the introduction of $\mathrm{H}_{2} \mathrm{O}_{2}$ or $\mathrm{H}_{2} \mathrm{O}_{2}-\mathrm{TiO}_{2}$. This may be due to decomposition of $\mathrm{H}_{2} \mathrm{O}_{2}$ into oxygen and $\mathrm{s}$ at the Ti substrate. Ti possesses a higher catalytic activity in the decomposition of $\mathrm{H}_{2} \mathrm{O}_{2}$ than its oxide form $\mathrm{TiO}_{2}$ (Tengvall et al. 1989). The presence of a protective oxide layer may initially inhibit the interaction of $\mathrm{Ti}$ and $\mathrm{H}_{2} \mathrm{O}_{2}$ and cause the observed delay until bubbling occurred. The $\mathrm{TiO}_{2}$ layer on top of the $\mathrm{Ti}$ surface is comparably thin and is likely to be broken-up by $\mathrm{H}_{2} \mathrm{O}_{2}$. The ruptured oxide layer may enable the interaction between metallic $\mathrm{Ti}$ and $\mathrm{H}_{2} \mathrm{O}_{2}$ which consequently leads to the observed gas evolution. This gas evolution may contribute substantially to the eradication of biofilms by physically removing bacteria and biofilm components from the surface.

The antibacterial effect of $\mathrm{H}_{2} \mathrm{O}_{2}-\mathrm{TiO}_{2}$ suspensions may further be limited due to the formation of $\mathrm{TiO}_{2}$ agglomerates (Figure 2). The occurrence of clusters in similar conditions has been described earlier for the nanoparticles used in this study (Wiedmer et al. 2016). Agglomeration reduces the number of active sites for the catalytic decomposition of $\mathrm{H}_{2} \mathrm{O}_{2}$ but more importantly may reduce the probability of contact between the bacterial wall and the oxidative $\mathrm{TiO}_{2}$ surface. Adverse effects of $\mathrm{TiO}_{2}$ clusters, such as the alteration of the implant surface or the cytotoxicity of released nanoparticles, may even hamper the re-osseointegration of decontaminated surfaces. 
Future research is therefore necessary to clarify the role of residual $\mathrm{TiO}_{2}$ agglomerates on the implant surface.

Compared to all other tested agents, $\mathrm{H}_{2} \mathrm{O}_{2}$ and $\mathrm{H}_{2} \mathrm{O}_{2}-\mathrm{TiO}_{2}$ showed the highest capacity to eradicate biofilm and remove adherent bacteria from the surface. The ability of $\mathrm{H}_{2} \mathrm{O}_{2}$ to disrupt bacterial biofilm has been observed earlier (Gustumhaugen et al. 2014; Henderson et al. 2013; Presterl et al. 2007) and is related to oxidation of several cellular components and potentially the gas evolution described above. The removal of attached microorganisms and also endo- and exotoxins from contaminated surfaces is a key aim in surgical peri-implantitis treatment (Kreisler et al. 2005; Takasaki et al. 2007). The most common strategy to achieve this aim is to combine mechanical debridement with adjunctive use of antimicrobial agents. Currently used approaches to physically remove biofilm from contaminated surfaces are often insufficient (Schwarz et al. 2006) or fail to retain the original implant surface unaltered (Deppe et al. 2002; Kreisler et al. 2005). Therefore, the capacity of $\mathrm{H}_{2} \mathrm{O}_{2}$-based treatments to actively reduce bacteria mass may contribute to a more efficient decontamination.

In contrast to $\mathrm{H}_{2} \mathrm{O}_{2}$ and $\mathrm{H}_{2} \mathrm{O}_{2}-\mathrm{TiO}_{2}, \mathrm{CHX}$ was not able to actively reduce biofilm mass (Figure 2) but was effective in preventing bacterial regrowth. This is supported by live/dead staining (Figure 2) where no vital bacteria were found on surfaces treated with this agent. CHX is frequently used in dentistry (Quirynen et al. 2000) and the strong bactericidal effect of CHX against various strains has been reported in numerous studies (Cervone et al. 1990; Ercan et al. 2006; Sassone et al. 2008; Vianna et al. 2004). The mechanism of action is linked to the rapid uptake of CHX by bacteria and the subsequent damage of the microbial membrane (McDonnell \& Russell 1999). The strong bactericidal effect of $\mathrm{CHX}$ compared to $\mathrm{H}_{2} \mathrm{O}_{2}$ and $\mathrm{H}_{2} \mathrm{O}_{2}-\mathrm{TiO}_{2}$ may be advantageous in peri-implantitis treatment, in which the inactivation of the microorganism is a key requirement (Lindhe et al. 2008). However, CHX has also been shown to be cytotoxic against different cell types which are related to early wound healing and should therefore be used cautiously in open wounds (Giannelli et al. 2008; Pucher \& Daniel 1992). The inability of CHX to detach biofilm, as demonstrated by a uniform layer of dead bacteria on the CHX treated surfaces, may further be disadvantageous in peri-implantitis treatment, by forming a foundation on which other bacteria may adhere to. This is particularly relevant in view of the commonly used techniques, which often fail to remove adherent biofilm from implant surfaces (Schwarz et al. 2006). 
The ultimate goal in the decontamination of dental implants is to prevent reinfection and promote re-osseointegration. Therefore, decontamination generally aims at the restoration of the original, microbe-free implant surface. The treatment with either $\mathrm{CHX}$ or $\mathrm{H}_{2} \mathrm{O}_{2}$-based agents could not achieve this goal in the tested in vitro setup. It is therefore suggested that a combined approach could be used to overcome the limitations of each agent. In a first step, $\mathrm{H}_{2} \mathrm{O}_{2}$ or $\mathrm{H}_{2} \mathrm{O}_{2}$ $\mathrm{TiO}_{2}$ is used to detach a great amount of biofilm only leaving a few viable cells on the surface. In a second step, $\mathrm{CHX}$ or an equivalent bactericidal agent is used to efficiently kill remaining microbes. The consequent dead organic matter left on the implant surface may be removed by phagocytic host cells or thorough rinsing in a clinical situation. Further research is needed to assess the potentially synergistic effects of this combined strategy for implant decontamination. 


\section{Conclusion}

This study investigated the antibacterial effect of $\mathrm{H}_{2} \mathrm{O}_{2}-\mathrm{TiO}_{2}$ suspensions in the decontamination of Ti implant surfaces which have been inoculated with a biofilm forming $S$. epidermidis strain. The addition of $\mathrm{TiO}_{2}$ nanoparticles enhanced the antibacterial effect of $\mathrm{H}_{2} \mathrm{O}_{2}$ and may be considered as an alternative approach for chemical decontamination in periimplantitis treatment. Further in vitro studies are necessary to optimise the decontamination efficacy of $\mathrm{H}_{2} \mathrm{O}_{2}-\mathrm{TiO}_{2}$ suspensions, e.g. by the use of adjunctive UV irradiation, but also to assess the potentially cytotoxic effect of $\mathrm{TiO}_{2}$ nanoparticles which remained on the implant surface. 


\section{Acknowledgment}

This study was supported by Eureka-Eurostars Project (Application E!8320 NuGel) and the Norwegian Research Council (Grant 257569). The authors thank Heidi A. Åmdal (Department of Oral Biology, University of Oslo) for technical laboratory assistance and Michael Otto for kindly providing us with $S$. epidermidis Xen 43 at no charge.

\section{Supplementary material}

The supplementary information is available free of charge on the Biofouling website at DOI: 10.1080/08927014.2017.1322585. 


\section{References}

Anpo M, Che M, Fubini B, Garrone E, Giamello E, Paganini M. 1999. Generation of superoxide ions at oxide surfaces. Top. Catal. 8:189-198. doi:http://dx.doi.org/10.1023/A:1019117328935

Atiyeh BS, Dibo SA, Hayek SN. 2009. Wound cleansing, topical antiseptics and wound healing. Int. Wound J. 6:420-430. doi:http://dx.doi.org/10.1111/j.1742-481X.2009.00639.x

Botero JE, González AM, Mercado RA, Olave G, Contreras A. 2005. Subgingival Microbiota in PeriImplant Mucosa Lesions and Adjacent Teeth in Partially Edentulous Patients. J. Periodontol. 76:14901495. doi:http://dx.doi.org/10.1902/jop.2005.76.9.1490

Bürgers R, Witecy C, Hahnel S, Gosau M. 2012. The effect of various topical peri-implantitis antiseptics on Staphylococcus epidermidis, Candida albicans, and Streptococcus sanguinis. Arch. Oral Biol. 57:940-947. doi:http://dx.doi.org/10.1016/i.archoralbio.2012.01.015

Carcuac O, Abrahamsson I, Charalampakis G, Berglundh T. 2015. The effect of the local use of chlorhexidine in surgical treatment of experimental peri-implantitis in dogs. J. Clin. Periodontol. 42:196-203. doi:http://dx.doi.org/10.1111/icpe.12332

Carcuac O, Derks J, Charalampakis G, Abrahamsson I, Wennström J, Berglundh T. 2016. Adjunctive systemic and local antimicrobial therapy in the surgical treatment of peri-implantitis: a randomized controlled clinical trial. J. Dent. Res. 95:50-57. doi:http://dx.doi.org/10.1177/0022034515601961

Cervone F, Tronstad L, Hammond B. 1990. Antimicrobial effect of chlorhexidine in a controlled release delivery system. Dent. Traumatol. 6:33-36. doi:http://dx.doi.org/10.1111/j.1600-9657.1990.tb00384.x Claffey N, Clarke E, Polyzois I, Renvert S. 2008. Surgical treatment of peri-implantitis. J. Clin. Periodontol. 35:316-332. doi:http://dx.doi.org/10.1111/j.1600-051X.2008.01277.x

D'Souza SF. 2001. Microbial biosensors. Biosens. Bioelectron. 16:337-353.

doi:http://dx.doi.org/10.1016/S0956-5663(01)00125-7

Darveau RP. 2010. Periodontitis: a polymicrobial disruption of host homeostasis. Nat Rev Micro. 8:481-490. doi:http://dx.doi.org/10.1038/nrmicro2337

de Waal YCM, Raghoebar GM, Huddleston Slater JJR, Meijer HJA, Winkel EG, van Winkelhoff AJ. 2013. Implant decontamination during surgical peri-implantitis treatment: a randomized, double-blind, placebo-controlled trial. J. Clin. Periodontol. 40:186-195. doi:http://dx.doi.org/10.1111/jcpe.12034 Deppe H, Greim H, Brill T, Wagenpfeil S. 2002. Titanium deposition after peri-implant care with the carbon dioxide laser. Int. J. Oral Maxillofac. Implants. 17.

Drosou A, Falabella A, Kirsner RS. 2003. Antiseptics on wounds: an area of controversy. Wounds. 15:149-166.

Ercan E, Dalli M, Dülgergil ÇT. 2006. In vitro assessment of the effectiveness of chlorhexidine gel and calcium hydroxide paste with chlorhexidine against Enterococcus faecalis and Candida albicans. Oral Surg. Oral Med. Oral Pathol. Oral Radiol. Endod. 102:e27-e31.

doi:http://dx.doi.org/10.1016/j.tripleo.2006.02.022

Fenoglio I, Greco G, Livraghi S, Fubini B. 2009. Non-UV-induced radical reactions at the surface of $\mathrm{TiO}_{2}$ nanoparticles that may trigger toxic responses. Chem. - Eur. J. 15:4614-4621.

doi:http://dx.doi.org/10.1002/chem.200802542

Gaupp R, Ledala N, Somerville GA. 2012. Staphylococcal response to oxidative stress. Front. Cell. Infect. Microbiol. 2:33. doi:http://dx.doi.org/10.3389/fcimb.2012.00033

Giannelli M, Chellini F, Margheri M, Tonelli P, Tani A. 2008. Effect of chlorhexidine digluconate on different cell types: a molecular and ultrastructural investigation. Toxicol. In Vitro. 22:308-317. doi:http://dx.doi.org/10.1016/j.tiv.2007.09.012

Gosau M, Hahnel S, Schwarz F, Gerlach T, Reichert TE, Bürgers R. 2010. Effect of six different periimplantitis disinfection methods on in vivo human oral biofilm. Clin. Oral Implants Res. 21:866-872. doi:http://dx.doi.org/10.1111/j.1600-0501.2009.01908.x

Gustumhaugen E, Lönn-Stensrud J, Scheie AA, Lyngstadaas S, Ekfeldt A, Taxt-Lamolle S. 2014. Effect of chemical and mechanical debridement techniques on bacterial re-growth on rough titanium surfaces: an in vitro study. Clin. Oral Implants Res. 25:707-713. doi:http://dx.doi.org/10.1111/clr.12130 Halliwell B, Gutteridge JM. 2007. Free radicals in biology and medicine. Oxford: Oxford University Press.

Heitz-Mayfield LJA, Lang NP. 2010. Comparative biology of chronic and aggressive periodontitis vs. peri-implantitis. Periodontology 2000. 53:167-181. doi:http://dx.doi.org/10.1111/j.1600- 
Henderson E, Schneider S, Petersen FC, Haugen HJ, Wohlfahrt JC, Ekstrand K, Ekfeldt A. 2013. Chemical debridement of contaminated titanium surfaces: an in vitro study. Acta Odontol. Scand. 71:957-964. doi:http://dx.doi.org/10.3109/00016357.2012.734423

Karring ES, Stavropoulos A, Ellegaard B, Karring T. 2005. Treatment of peri-implantitis by the Vector ${ }^{\circledR}$ system. Clin. Oral Implants Res. 16:288-293. doi:http://dx.doi.org/10.1111/j.1600-0501.2005.01141.x Kreisler M, Kohnen W, Christoffers A-B, Götz H, Jansen B, Duschner H, D'Hoedt B. 2005. In vitro evaluation of the biocompatibility of contaminated implant surfaces treated with an $\mathrm{Er}$ : YAG laser and an air powder system. Clin. Oral Implants Res. 16:36-43. doi:http://dx.doi.org/10.1111/j.16000501.2004.01056.x

Kronström M, Svenson B, Hellman M, Persson GR. 2001. Early Implant Failures in Patients Treated with Brånemark System Titanium Dental Implants: A Retrospective Study. Int. J. Oral Maxillofac. Implants. 16.

Larsen T, Fiehn N-E. 1996. Resistance of Streptococcus sanguis biofilms to antimicrobial agents. APMIS. 104:280-284. doi:http://dx.doi.org/10.1111/j.1699-0463.1996.tb00718.x Leonhardt Å, Dahlén G, Renvert S. 2003. Five-year clinical, microbiological, and radiological outcome following treatment of peri-implantitis in man. J. Periodontol. 74:1415-1422. doi:http://dx.doi.org/10.1902/iop.2003.74.10.1415 Leonhardt Å, Renvert S, Dahlén G. 1999. Microbial findings at failing implants. Clin. Oral Implants Res. 10:339-345. doi:http://dx.doi.org/10.1034/j.1600-0501.1999.100501.x

Lindhe J, Meyle J, on behalf of Group DotEWoP. 2008. Peri-implant diseases: consensus report of the sixth european workshop on periodontology. J. Clin. Periodontol. 35:282-285.

doi:http://dx.doi.org/10.1111/j.1600-051X.2008.01283.x

Linley E, Denyer SP, McDonnell G, Simons C, Maillard J-Y. 2012. Use of hydrogen peroxide as a biocide: new consideration of its mechanisms of biocidal action. J. Antimicrob. Chemother. 67:15891596. doi:http://dx.doi.org/10.1093/jac/dks129

Mah T-FC, O'Toole GA. 2001. Mechanisms of biofilm resistance to antimicrobial agents. Trends Microbiol. 9:34-39. doi:http://dx.doi.org/10.1016/S0966-842X(00)01913-2

Marincs F. 2000. On-line monitoring of growth of Escherichia coli in batch cultures by bioluminescence. Appl. Microbiol. Biotechnol. 53:536-541.

doi:http://dx.doi.org/10.1007/s002530051653

McDonnell G, Russell AD. 1999. Antiseptics and disinfectants: activity, action, and resistance. Clin. Microbiol. Rev. 12:147-179.

Mombelli A, Lang NP. 1998. The diagnosis and treatment of peri-implantitis. Periodontology 2000. 17:63-76. doi:http://dx.doi.org/10.1111/j.1600-0757.1998.tb00124.x

Persson GR, Renvert S. 2014. Cluster of Bacteria Associated with Peri-Implantitis. Clinical Implant Dentistry and Related Research. 16:783-793. doi:http://dx.doi.org/10.1111/cid.12052

Presterl E, Suchomel M, Eder M, Reichmann S, Lassnigg A, Graninger W, Rotter M. 2007. Effects of alcohols, povidone-iodine and hydrogen peroxide on biofilms of Staphylococcus epidermidis. J. Antimicrob. Chemother. 60:417-420. doi:http://dx.doi.org/10.1093/jac/dkm221

Pucher JJ, Daniel C. 1992. The effects of chlorhexidine digluconate on human fibroblasts in vitro. J. Periodontol. 63:526-532. doi:http://dx.doi.org/10.1902/jop.1992.63.6.526

Quirynen M, De Soete M, Van Steenberghe D. 2002. Infectious risks for oral implants: a review of the literature. Clin. Oral Implants Res. 13:1-19. doi:http://dx.doi.org/10.1034/i.1600-0501.2002.130101.x Quirynen M, Mongardini C, De Soete M, Pauwels M, Coucke W, Van Eldere J, Van Steenberghe D. 2000. The role of chlorhexidine in the one-stage full-mouth disinfection treatment of patients with advanced adult periodontitis. J. Clin. Periodontol. 27:578-589. doi:http://dx.doi.org/10.1034/j.1600051x.2000.027008578.x

Renvert S, Polyzois I, Claffey N. 2012. Surgical therapy for the control of peri-implantitis. Clin. Oral Implants Res. 23:84-94. doi:http://dx.doi.org/10.1111/j.1600-0501.2012.02554.x

Roberts AP, Mullany P. 2010. Oral biofilms: a reservoir of transferable, bacterial, antimicrobial resistance. Expert Rev. Anti-Infect. Ther. 8:1441-1450. doi:http://dx.doi.org/10.1586/eri.10.106 Romanos GE, Javed F, Delgado-Ruiz RA, Calvo-Guirado JL. 2015. Peri-implant diseases: a review of treatment interventions. Dent. Clin. North Am. 59:157-178.

doi:http://dx.doi.org/10.1016/j.cden.2014.08.002

Romanos GE, Ko H-H, Froum S, Tarnow D. 2009. The use of $\mathrm{CO}_{2}$ laser in the treatment of periimplantitis. Photomed. Laser Surg. 27:381-386. doi:http://dx.doi.org/10.1089/pho.2008.2280 
Sanchez LD, Taxt-Lamolle SFM, Hole EO, Krivokapic A, Sagstuen E, Haugen HJ. 2013. TiO 2 suspension exposed to $\mathrm{H}_{2} \mathrm{O}_{2}$ in ambient light or darkness: degradation of methylene blue and EPR evidence for radical oxygen species. Appl. Catal., B. 142:662-667.

doi:http://dx.doi.org/10.1016/j.apcatb.2013.05.017

Sassone LM, Fidel RAS, Murad CF, Fidel SR, Hirata R. 2008. Antimicrobial activity of sodium hypochlorite and chlorhexidine by two different tests. Aust. Endod. J. 34:19-24.

doi:http://dx.doi.org/10.1111/j.1747-4477.2007.00071.x

Sbordone L, Bortolaia C. 2003. Oral microbial biofilms and plaque-related diseases: microbial communities and their role in the shift from oral health to disease. Clin. Oral Investig. 7:181-188. doi:http://dx.doi.org/10.1007/s00784-003-0236-1

Schwarz F, Jepsen S, Herten M, Sager M, Rothamel D, Becker J. 2006. Influence of different treatment approaches on non-submerged and submerged healing of ligature induced peri-implantitis lesions: an experimental study in dogs. J. Clin. Periodontol. 33:584-595.

doi:http://dx.doi.org/10.1111/i.1600-051X.2006.00956.x

Schwarz F, Papanicolau P, Rothamel D, Beck B, Herten M, Becker J. 2006. Influence of plaque biofilm removal on reestablishment of the biocompatibility of contaminated titanium surfaces. J.

Biomed. Mater. Res., Part A. 77A:437-444. doi:http://dx.doi.org/10.1002/jbm.a.30628

Schwarz F, Sahm N, Iglhaut G, Becker J. 2011. Impact of the method of surface debridement and decontamination on the clinical outcome following combined surgical therapy of peri-implantitis: a randomized controlled clinical study. J. Clin. Periodontol. 38:276-284.

doi:http://dx.doi.org/10.1111/j.1600-051X.2010.01690.x

Stewart PS, Roe F, Rayner J, Elkins JG, Lewandowski Z, Ochsner UA, Hassett DJ. 2000. Effect of catalase on hydrogen peroxide penetration into Pseudomonas aeruginosa biofilms. Appl. Environ. Microbiol. 66:836-838. doi:http://dx.doi.org/10.1128/aem.66.2.836-838.2000

Takasaki AA, Aoki A, Mizutani K, Kikuchi S, Oda S, Ishikawa I. 2007. Er:YAG laser therapy for periimplant infection: a histological study. Lasers Med. Sci. 22:143-157.

doi:http://dx.doi.org/10.1007/s10103-006-0430-x

Tengvall P, Lundström I, Sjöqvist L, Elwing H, Bjursten LM. 1989. Titanium-hydrogen peroxide interaction: model studies of the influence of the inflammatory response on titanium implants.

Biomaterials. 10:166-175. doi:http://dx.doi.org/10.1016/0142-9612(89)90019-7

Ungvári K, Pelsöczi IK, Kormos B, Oszkó A, Rakonczay Z, Kemény L, Radnai M, Nagy K, Fazekas A, Turzó K. 2010. Effects on titanium implant surfaces of chemical agents used for the treatment of periimplantitis. J. Biomed. Mater. Res., Part B. 94B:222-229. doi:http://dx.doi.org/10.1002/jbm.b.31644 Vianna ME, Gomes BPFA, Berber VB, Zaia AA, Ferraz CCR, de Souza-Filho FJ. 2004. In vitro evaluation of the antimicrobial activity of chlorhexidine and sodium hypochlorite. Oral Surg. Oral Med. Oral Pathol. Oral Radiol. Endod. 97:79-84. doi:http://dx.doi.org/10.1016/S1079-2104(03)00360-3

Vuong C, Kocianova S, Yu J, Kadurugamuwa JL, Otto M. 2008. Development of real-time in vivo imaging of device-related Staphylococcus epidermidis infection in mice and influence of animal immune status on susceptibility to infection. J. Infect. Dis. 198:258-261.

doi:http://dx.doi.org/10.1086/589307

Wiedmer D, Sagstuen E, Welch K, Haugen HJ, Tiainen H. 2016. Oxidative power of aqueous nonirradiated $\mathrm{TiO}_{2}-\mathrm{H}_{2} \mathrm{O}_{2}$ suspensions: methylene blue degradation and the role of reactive oxygen species. Appl. Catal., B. 198:9-15. doi:http://dx.doi.org/10.1016/i.apcatb.2016.05.036

Zaura-Arite E, van Marle J, ten Cate JM. 2001. Confocal microscopy study of undisturbed and chlorhexidine-treated dental biofilm. J. Dent. Res. 80:1436-1440.

doi:http://dx.doi.org/10.1177/00220345010800051001

Zitzmann NU, Berglundh T. 2008. Definition and prevalence of peri-implant diseases. J. Clin. Periodontol. 35:286-291. doi:http://dx.doi.org/10.1111/i.1600-051X.2008.01274.x. 